\title{
Recent developments in testis tissue xenografting
}

\author{
Jose R Rodriguez-Sosa and Ina Dobrinski \\ School of Veterinary Medicine, Center for Animal Transgenesis and Germ Cell Research, New Bolton Center, \\ University of Pennsylvania, Kennett Square, Pennsylvania 19348, USA
}

Correspondence should be addressed to I Dobrinski who is now at Department of Comparative Biology and Experimental Medicine, University of Calgary, 3330 Hospital Drive NW, Calgary, Canada AB T2N 4N1; Email: idobrins@ucalgary.ca

\begin{abstract}
Development of the mammalian testis and spermatogenesis involve complex processes of cell migration, proliferation, differentiation, and cell-cell interactions. Although our knowledge of these processes has increased in the last few decades, many aspects still remain unclear. The lack of suitable systems that allow to recapitulate and manipulate both testis development and spermatogenesis ex situ has limited our ability to study these processes. In the last few years, two observations suggested novel strategies that will improve our ability to study and manipulate mammalian spermatogenesis: i) testis tissue from immature animals transplanted ectopically into immunodeficient mice is able to respond to mouse gonadotropins and to initiate and complete differentiation to the level where fertilization-competent sperm are obtained, and ii) isolated testis cells are able to organize and rearrange into seminiferous cords that subsequently undergo complete development, including production of viable sperm. The current paper reviews recent advances that have been obtained with both techniques that represent novel opportunities to explore testis development and spermatogenesis in diverse mammalian species.

Reproduction (2009) 138 187-194
\end{abstract}

\section{Introduction}

Male fertility requires close, complex, and dynamic interactions of germ cells and supporting Sertoli cells in the epithelium of the seminiferous tubules. Organization of the seminiferous epithelium is a long process that starts early in life with the migration of primordial germ cells to the gonadal ridges of the embryo and the formation of seminiferous cords in conjunction with primitive Sertoli cells and peritubular myoid cells. After birth, the cords transform into tubules, and after a period of Sertoli cell proliferation germ cells actively divide and differentiate to give rise to the first wave of spermatogenesis. The male germ cells (spermatogonia, spermatocytes, and spermatids) are located in the seminiferous tubules in intimate association with somatic cells, in particular Sertoli cells, which form a simple columnar epithelium, resting on the basal lamina of the tubules and extending elaborate processes to surround the germ cells throughout the epithelium (Fig. 1). Surrounding peritubular myoid cells located at the extratubular side of the basal lamina contribute to the wall of the tubules (Orth 1993).

Testis development and spermatogenesis are regulated by numerous factors and although our knowledge of them has increased significantly, it is still far from being complete, particularly in postnatal development and in non-rodent species (Merchant-Larios \& Moreno-Mendoza 2001). In the last few decades, important discoveries have provided new alternatives with unprecedented opportunities for the study of testis development and spermatogenesis. Germ cell transplantation in the rodent model has proven to be an invaluable tool for the study of spermatogenesis and spermatogonial stem cell biology (Brinster \& Avarbock 1994, Brinster \& Zimmermann 1994, Brinster 2007). The technique has now also been successfully established in pigs (Honaramooz et al. 2002a), goats (Honaramooz et al. 2003a, 2003b, 2008b), cattle (Izadyar et al. 2003, Herrid et al. 2006), monkeys (Schlatt et al. 1999, 2002a) sheep (Rodriguez-Sosa et al. 2006, 2009), and dogs (Kim et al. 2008); and although its use in these species is now a realistic option, further studies are needed before this approach becomes more widely applicable (Dobrinski \& Travis 2007). One current limitation is that germ cell transplantation to study spermatogenesis in these species and to manipulate their germ cells is logistically difficult and expensive. Therefore, novel alternatives that allow procedures to be performed without extensive experimentation in the target species are highly desirable. Transplantation of germ cells from donors of larger species into mouse testes results in incomplete spermatogenesis, with no differentiation beyond the spermatogonial stage. This is presumably due to an incompatibility between the donor germ cells and the microenvironment of the mouse testis 


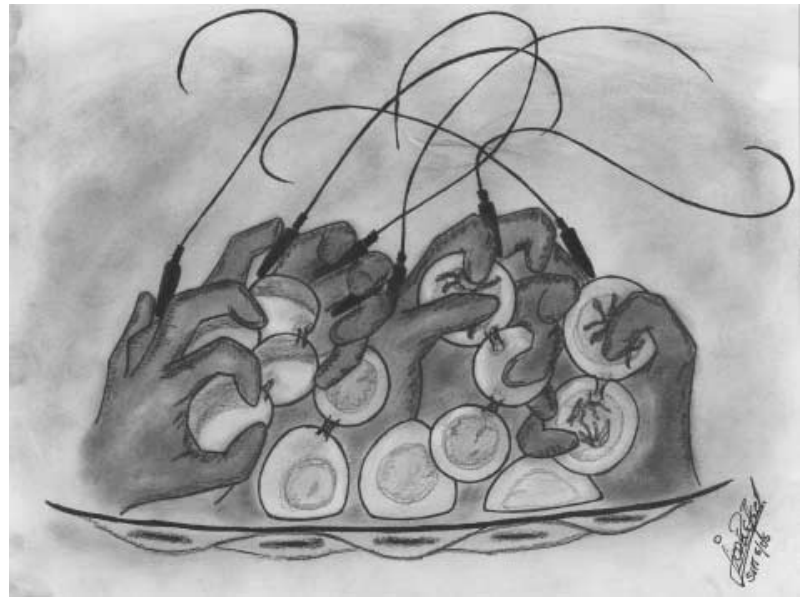

Figure 1 Artistic rendition of the organization of the seminiferous epithelium in the adult mammalian testis. Sertoli cells, represented by the hands, are dynamic units continuously changing shape to accommodate proliferating and differentiating germ cells located between them. Sertoli cells are located on the basal lamina of the tubules opposite to peritubular myoid cells, which also contribute to the wall of the tubules.

(Dobrinski et al. 1999, 2000, Nagano et al. 2001, 2002). Presence of an appropriate surrounding somatic compartment therefore seems to be necessary for germ cells to proliferate and differentiate. Recently, two important discoveries have shown that co-transplantation of the donor germ cells with their surrounding somatic compartment into the rodent host preserves the necessary compatibility, yet still allows experimentation in the rodent host. First, it was reported that testis pieces from immature domestic males transplanted ectopically to mice were able to respond to host gonadotropins and developed similarly to development in situ, including the formation of fertilization competent sperm (Honaramooz et al. 2002b). More recently, it was reported that isolated testicular somatic cells and germ cells from neonatal males transplanted under the dorsal skin of mice rearrange to generate complete testis tissue that exhibits both endocrine and spermatogenic functions (Honaramooz et al. 2007, Kita et al. 2007). Whereas transplantation of testis cells mimics the complete development process, transplantation of tissue recapitulates the postnatal phase. These strategies are technically much easier than spermatogonial transplantation in larger animals for manipulation and study of testis development and spermatogenesis. Since it has been shown that sperm obtained from testis tissue xenografts can be used for ICSI to produce embryos and offspring (Honaramooz et al. 2002a, 2002b, 2004, 2008a, Schlatt et al. 2003), these strategies also represent new approaches for preserving the germ line of valuable males or endangered species (Dobrinski 2005, Paris \& Schlatt 2007). Here, we review some of the more recent advances accomplished with ectopic transplantation of tissue and cells from larger species into immunodeficient mice.

\section{Xenotransplantation of testis tissue}

At first glance, the testis does not appear to be a suitable tissue for grafting because of the complexity of the seminiferous epithelium and the architecture of its vascular and duct systems. However, transplantation of testicular tissue has been performed since 1924, and has provided important insights into testicular function. Autologous and homologous transplantation of testicular tissue have been reviewed by Gosden \& Aubard (1996a, 1996b). Immunodeficient lines of mice now allow xenotransplantation of testicular and other tissues (Paris et al. 2004), which makes it possible to transplant tissue from large animals into mouse hosts (Dobrinski 2005). Xenotransplantation of testicular tissue (human fetal testis into the abdominal wall of adult nude mice) was first performed in 1974 (Skakkebaek et al. 1974). Subsequently Hochereau-de-Reviers \& Perreau (1997) transplanted ovine fetal testis into the scrotum of intact nude mice and reported differentiation of gonocytes into spermatogonia and primary spermatocytes. However, complete cross species spermatogenesis was first reported in 2002 (Honaramooz et al. $2002 b)$. In that report, pieces of testis tissue from newborn pigs and goats were able to survive and displayed complete development with production of sperm. Since then, testis tissue xenografting has been tested in numerous species. In most studies, the testicular tissue that is transplanted is small cubes of $\sim 0.5-1 \mathrm{~mm}^{3}, 3-5 \mathrm{mg}$, or $10 \mathrm{mg}$ (Honaramooz et al. 2002b, Schlatt et al. 2002b, Schmidt et al. 2006a, 2006b). These tissue fragments are transplanted into multiple sites under the dorsal skin on either side of the spinal cord, 2-8 pieces/mouse. The recipients are immune-deficient mice, usually nude (T-cell deficient) mice (Honaramooz et al. 2002b, Schlatt et al. 2002b, Oatley et al. 2004, 2005, Rathi et al. 2005, 2006, Zeng et al. 2006), but severe-combined immunodeficient mice (T- and B-cell deficient mice) have also been used (Honaramooz et al. 2004, Snedaker et al. 2004, Rathi et al. 2005, 2006, Schlatt et al. 2006). No difference has been found between xenografts transplanted into these two strains (Rathi et al. 2005, 2006, Geens et al. 2006). The recipients are castrated prior to or during the transplantation surgery. With the exception of the marmoset (Schlatt et al. 2002b, Wistuba et al. 2004), testicular grafts from all species evaluated so far are able to survive and respond to mouse gonadotropins once they are transplanted under the dorsal skin of castrated mice. This response is characterized by the development of immature xenografts, and the production of spermatozoa (Fig. 2) 


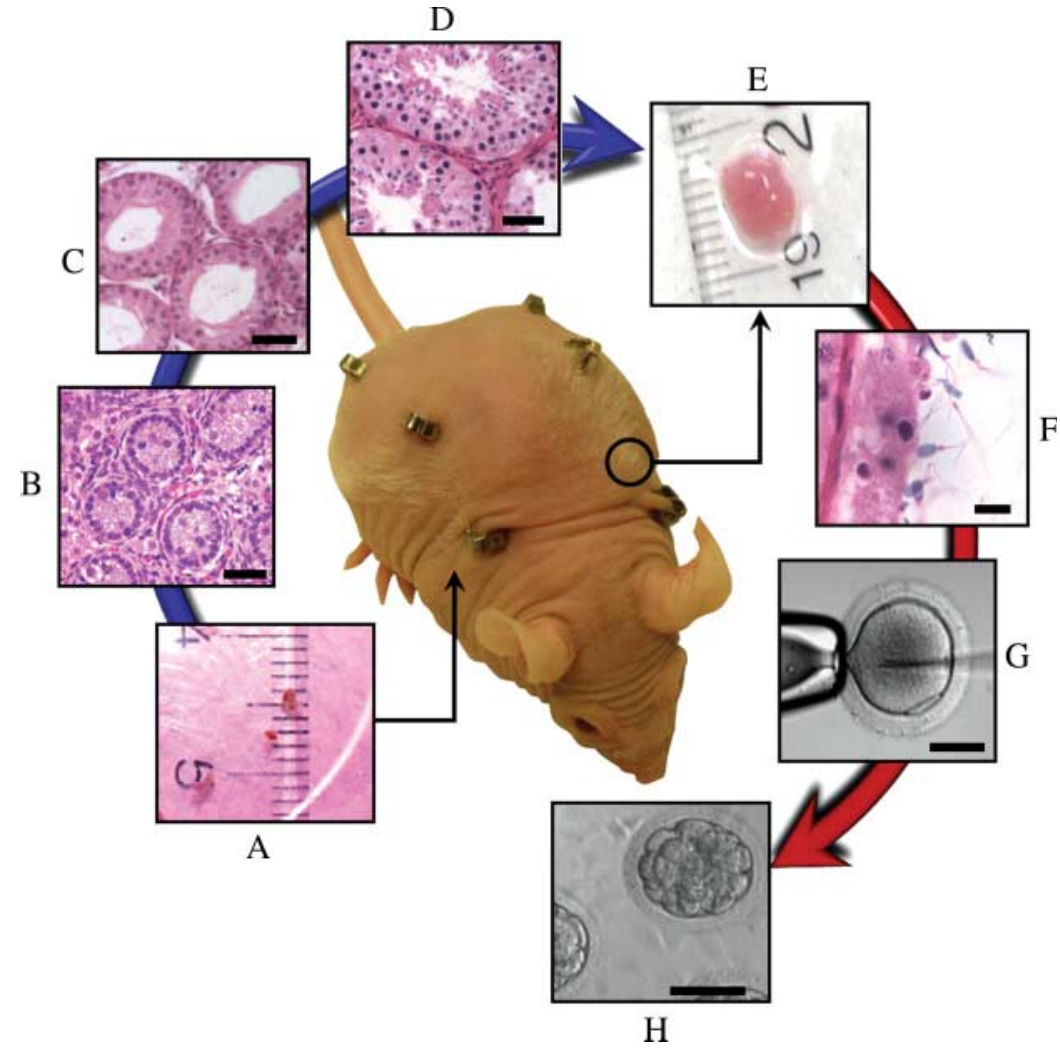

Figure 2 Ectopic xenografting of immature testis tissue from large animals into immunodeficient mice. Fragments of immature donor testis $\left(\sim 1 \mathrm{~mm}^{3}\right)$ transplanted under the dorsal skin of immunodeficient mice (A and $B$ ) are able to survive and respond to mouse gonadotropins. As a result, testis tissue undergoes complete development, including the formation of fertilization competent sperm (C-F). Once testis xenografts are collected (E), they can be used for analysis or to obtain sperm for ICSI (G) and embryo production $(\mathrm{H})$. Bars equal $50 \mu \mathrm{m}(\mathrm{B}-\mathrm{D}, \mathrm{G}$ and $\mathrm{H})$ or $10 \mu \mathrm{m}(\mathrm{F})$. and androgens. Several factors affect testis tissue survival and function after transplantation. So far, the best understood are the effects of donor species and of the age and developmental stage of the donor.

\section{Effects of donor species}

Testis tissue xenografting has been evaluated in numerous species with variable results. Three major variables have been affected by the species: development through spermatogenesis; timing of spermatogenic development; and efficiency of spermatogenesis (Table 1). Regarding the first variable, testis tissue from species phylogenetically distant from mice such as rhesus monkeys, cattle, goats, cats, and pigs is responsive to host gonadotrophins as demonstrated by spermatogenesis after grafting. A notable exception is the marmoset, which appears insensitive to mouse $\mathrm{LH}$ due to a deletion in exon 10 of its $\mathrm{LH}$-receptor gene. This blocks androgen production and results in poor spermatogenesis after grafting (Schlatt et al. 2002b, Wistuba et al. 2004).

Shortening of the time required until first appearance of testicular sperm in immature testicular xenografts is evident in species like pig and monkey, and it is attributed to the capacity of transplanted tissue to immediately respond to the gonadotropins of the castrated adult recipient (Honaramooz et al. 2002b,
2004). Two notable exceptions are xenografts of testes from cattle and cats. In cattle, onset of spermatogenesis is slightly advanced or similar to testes in situ (Oatley et al. 2004, 2005, Rathi et al. 2005). In cats, this timing is delayed (Snedaker et al. 2004, Kim et al. 2007). Interestingly, similar to observations in other donor species, bovine and feline xenografts start developing earlier than in age-matched in situ controls, with a slight acceleration of the onset of meiosis. However, bovine germ cells seem to arrest at meiosis resulting in slight or no advance (Rathi et al. 2005). In cats, delay in the timing of testicular maturation may be controlled by the testis (Snedaker et al. 2004) or may be a result of an incompetence of the testis tissue to support full spermatogenesis for some time, suggesting an immaturity of some component within the feline testis xenograft (Kim et al. 2007).

The efficiency of spermatogenesis in xenografts is also species dependent. While the number of spermatozoa produced by pig and goat testicular xenografts was similar to that produced in normal testes on a 'per gram of tissue' basis (Honaramooz et al. 2002b), complete spermatogenesis does not occur in all seminiferous tubules in xenografts of cattle (Oatley et al. 2004, 2005, Rathi et al. 2005, Schmidt et al. 2006a, 2006b), horses (Rathi et al. 2006), cats (Snedaker et al. 2004, Kim et al. 2007), sheep (Zeng et al. 2006, Arregui 
Table 1 Development of testis tissue and spermatogenesis in ectopic testis xenografts.

\begin{tabular}{|c|c|c|c|c|c|}
\hline Species & Donor age & $\begin{array}{l}\text { \% Tubules with } \\
\text { complete } \\
\text { spermatogenesis }^{\mathrm{a}}\end{array}$ & Collection time ${ }^{b}$ & $\begin{array}{l}\text { Onset of } \\
\text { spermatogenesis }^{c}\end{array}$ & References \\
\hline Pig & 1-2 weeks & $52(7-98)$ & $7-8$ months & Advanced & $\begin{array}{l}\text { Honaramooz et al. }(2002 b) \text { and } \\
\text { Zeng et al. }(2006,2007)\end{array}$ \\
\hline Cattle & $1-8$ weeks & $<15$ & 24-36 weeks & $\begin{array}{l}\text { Similar or slightly } \\
\text { advanced }\end{array}$ & $\begin{array}{l}\text { Oatley et al. (2004, 2005), Rathi et al. } \\
\text { (2005) and Schmidt et al. (2006a, } \\
2006 b)\end{array}$ \\
\hline Goat & 4 weeks & Not mentioned & Not mentioned & Not determined & Honaramooz et al. (2002b) \\
\hline Sheep & $1-2$ weeks & $64(2-92)$ & $12-28$ weeks & $\begin{array}{l}\text { Similar or } \\
\text { advanced }\end{array}$ & $\begin{array}{l}\text { Zeng et al. (2006) and } \\
\quad \text { Arregui et al. (2008a) }\end{array}$ \\
\hline Horse & 2 weeks -4 years & $\sim 5^{\mathrm{d}}$ & 8 months & Not determined & Rathi et al. (2006) \\
\hline Cat & 1 week-15 months & $6-25^{\mathrm{e}}$ & 35-50 weeks & Delayed & $\begin{array}{l}\text { Snedaker et al. (2004) and } \\
\quad \text { Kim et al. (2007) }\end{array}$ \\
\hline Rhesus macaque & 3-13 months & $4(0-15)$ & 7 months & Advanced & $\begin{array}{l}\text { Honaramooz et al. (2004) and } \\
\text { Rathi et al. (2008) }\end{array}$ \\
\hline Human & Adult & 0 & - & - & $\begin{array}{l}\text { Geens et al. (2006) and } \\
\text { Schlatt et al. (2006) }\end{array}$ \\
\hline Mouse $^{f}$ & $1-2$ days & $\sim 10-20$ & 4-16 weeks & Similar & $\begin{array}{l}\text { Honaramooz et al. (2002b) and } \\
\quad \text { Schlatt et al. (2003) }\end{array}$ \\
\hline
\end{tabular}

${ }^{\mathrm{a}}$ Presence of elongated spermatids and/or sperm. ${ }^{\mathrm{b}}$ Collection time at which full spermatogenesis was observed. ${ }^{\mathrm{c}}$ In comparison with testis in situ. ${ }^{\mathrm{d}}$ Only in a 10-month-old donor. ${ }^{\mathrm{e}}$ In donors younger than 7 months of age. ${ }^{\mathrm{f}} \mathrm{Allog}$ rafting, included for comparison.

et al. 2008a), and rhesus monkeys (Honaramooz et al. 2004, Rathi et al. 2008). One potential reason for failure to achieve complete spermatogenic differentiation appears to be incomplete Sertoli cell maturation in the grafted tissue (Rathi et al. 2008).

\section{Age and developmental stage of donor}

The second most explored factor affecting testis xenograft survival and development is the age or developmental stage of the donor. Survival of xenografts decreases with the degree of maturity of the donor tissue. Tissue from adult donors shows poor survival and a marked tendency to degenerate making it unsuitable for transplantation (Schlatt et al. 2002b, Geens et al. 2006, Kim et al. 2007, Arregui et al. 2008b). Some spermatozoa were produced from transplanted adult mouse and human testicular tissue. However, these spermatozoa were believed to be from differentiating germ cells that completed spermatogenesis after grafting, rather than arising de novo from spermatogonial stem cells (Schlatt et al. 2002b, 2006, Geens et al. 2006). Degeneration of adult testis xenografts seems to occur faster in those species with higher spermatogenic activity such as pig and goat, and even in a particular species, degeneration is more severe in mature adult donors than in subadult donors (Arregui et al. 2008b). Several reasons have been proposed to explain poor survival of adult testis tissue, including lack of proliferation of Sertoli cells, increased sensitivity to ischemia, and a decreased angiogenic ability of the adult tissue (Schlatt et al. 2002b, Arregui et al. 2008a, 2008b).

Immature tissue shows the best survival. Tissue from neonatal and prepubertal donors displays better survival and support of spermatogenesis than that from donors in which maturation has been initiated. It appears that once meiosis has occurred consistently throughout the donor tissue, the ability of that tissue to survive as a xenograft and support spermatogenesis declines dramatically (Rathi et al. 2006, Kim et al. 2007). Ischemic damage is expected to occur in any type of transplantation, and an initial loss of germ cells has been described (Rathi et al. 2006). Recovery of germ cell numbers and establishment of spermatogenesis in testis xenografts must occur by proliferation and differentiation of spermatogonial stem cells (Rathi et al. 2006, Huang et al. 2008). Differences in stem cell cohorts between prepubertal and pubertal donors may contribute to differences in their ability to survive and support spermatogenesis. Moreover, it is also possible that the somatic cell components and later stages of germ cells contribute to this difference (Kim et al. 2007). By the time meiosis has started, Sertoli cells have matured and their proliferative activity decreases (Meachem et al. 2005), and this may contribute to a decreased ability of pubertal donors to replenish Sertoli cells lost after transplantation. On the other hand, meiotic and postmeiotic germ cells may be less likely to survive hypoxia after transplantation due to their dependence on oxidative metabolism (Rathi et al. 2006, Kim et al. 2007).

\section{Effects of recipient}

Most xenotransplantations have been into the subcutaneous tissue on the dorsal surface of the rodent host, although Shinohara et al. (2002) successfully transplanted immature rabbit testicular tissue into the testes of mice. There are differences in temperature and 
vascularity between these sites that would be expected to affect graft development and survival. Homologous transplantations in rats by Turner (1938) showed that the anterior chamber of the eye provided a better environment for testicular grafts than subcutaneous, intraperitoneal, intramuscular, and scrotal sites as measured by percentage survival of tissue and sperm production.

Most xenotransplantation studies have used castrated males as recipients. This avoids interference of the host testis in response of xenografts to host gonadotropins, and allows androgen production by graft Leydig cells to be monitored based on the weight and histology of the host seminal vesicles, the development of which is androgen dependent (Gosden \& Aubard 1996b). In addition, removal of the host testes releases the negative feedback on the mouse pituitary secretion of $\mathrm{FSH}$, resulting in increased levels of $\mathrm{FSH}$ at the time of grafting (Schlatt et al. 2003). These increased gonadotropin levels are thought to support Sertoli cell proliferation and graft development until a feedback axis is re-established between the grafted tissue and the host hypothalamus and pituitary. Already in 1938, Turner found that survival of homologous testicular grafts in rats was better (less degeneration, more sperm) when the recipient was castrated, and Rathi et al. (2006) observed that xenografts under the dorsal skin of mice did not develop in intact males. However, Shinohara et al. (2002) obtained functional sperm from rabbit testis xenografts into testes of intact mice. Therefore, while graft development generally is improved in castrated mouse hosts, there may be species-specific differences that will allow spermatogenesis to occur in grafts placed into intact male mice.

\section{Xenotransplantation of testis cells}

While testis tissue xenografting allows the maintenance of the integrity of the seminiferous epithelium, it does not allow easy manipulation of selected cell types in the testis. The morphogenic ability of isolated testis cells to reconstitute functional testis tissue and support spermatogenesis after transplantation opens new possibilities to accomplish that aim. Grafting of isolated testis cells has been developed more recently, and as such it has been explored less than testis tissue xenografting. Although the factors that affect testis tissue (reviewed above) may presumably have a similar effect on testis cells after transplantation, additional research is necessary to evaluate those effects. So far, this technique has successfully been evaluated with cells from newborn donors in pigs (Honaramooz et al. 2007), rodents (Kita et al. 2007), and sheep (Arregui et al. 2008a).

Formation of functional testis tissue from transplantation of isolated cells built on previous reports showing that co-transplantation of porcine Sertoli cells and pancreatic islets, to confer immunoprotection by
Sertoli cells, resulted in cord formation by Sertoli and peritubular myoid cells (Kin et al. 2002). Similarly, isolated rat testis cells transplanted under the kidney capsule of mice or maintained in culture and then transplanted ectopically had the ability to generate seminiferous cords (Dufour et al. 2002, Gassei et al. 2006). However, it remained to be demonstrated whether i) seminiferous tubules generated from isolated cells could form a functional stem cell niche, ii) germ cells could locate in this niche, and iii) interact with it to support complete spermatogenesis. To answer these questions, concentrated pellets from single-cell suspensions prepared from neonatal porcine testes, composed of $\sim 50 \%$ Sertoli cells, $5 \%$ germ cells, $20 \%$ peritubular myoid cells, and $10 \%$ Leydig cells, were transplanted under the dorsal skin of immunodeficient mice. After a few days, cells had rearranged into cord-like structures, and by 4 weeks cords transformed into tubules. By that time, germ cells contained in the tubules had migrated to the basal lamina and started to proliferate. After 30 weeks, complete spermatogenesis had occurred, and sperm were present in the lumen of $\sim 10 \%$ of the tubules (Honaramooz et al. 2007).

Similarly, de novo morphogenesis of testis tissue was also described when isolated testis cells from embryonic or neonatal mouse and rat were grafted ectopically to mouse hosts (Kita et al. 2007). In that study, isolated cells from newborn testes were mixed with cultured mouse germ line stem cells carrying a GFP marker and grafted into mouse hosts. In the reconstituted tissue, spermatogenesis progressed to the stage of round spermatids derived from the cultured cells. ICSI of these cells into mouse oocytes and embryo transfer resulted in the birth of normal pups expressing the GFP marker, demonstrating that haploid cells formed in the reconstituted testis tissue were capable to support complete development (Kita et al. 2007).

In a recent study in sheep, a heterogeneous cell suspension obtained from 2-week-old lambs was concentrated and transplanted under the dorsal skin of nude mice. Similar to pig testis morphogenesis, by 4 weeks after grafting lamb testis the cells had organized into tubules. No differentiated germ cells were observed $4,8,12$, and 16 weeks after transplantation. However, at 35 weeks, some tubules contained pachytene spermatocytes, and by 40 weeks after grafting, complete spermatogenesis had occurred (Arregui et al. 2008a). Taken together, these studies demonstrated the amazing capability of isolated postnatal testis cells to recapitulate testis development, rearrange into seminiferous cords, and undergo complete differentiation. Recently, the ability to form seminiferous tubules from isolated Sertoli cells after grafting into mouse hosts has also been demonstrated for bovine Sertoli cells (Zhang et al. 2008), and has been applied to the study of Sertoli cell function in the rat (Gassei et al. 2008). 


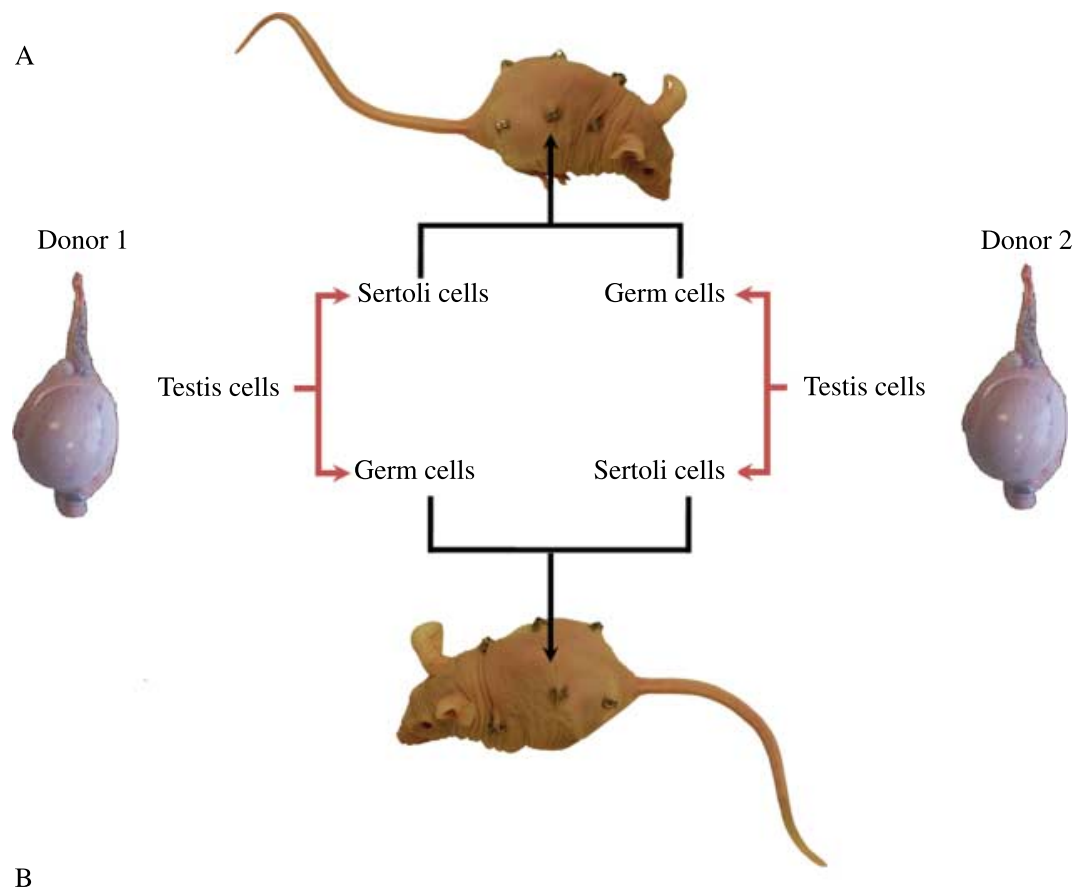

Figure 3 Potential applications of testis cell transplantation for the study of testis development and spermatogenesis. Isolated germ cells and somatic cells from different donors may be combined to study the effects of different cell types on testis development and spermatogenesis (A).

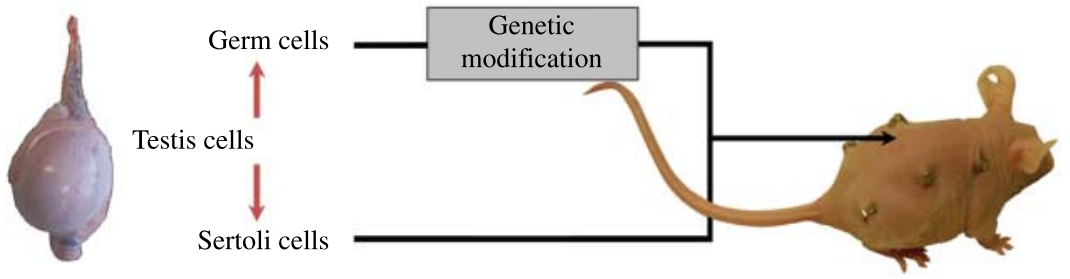
Isolated testis cells may be genetically modified before being combined with other testis cells for subsequent transplantation. In the example illustrated here, genetic modification of germ cells could be used to elucidate the role of specific genes in testis morphogenesis and spermatogenesis or to produce transgenic sperm for ICSI (B).

\section{Applications of testis tissue and testis cell transplantation}

Ectopic testis tissue grafting represents a new option for male germ line preservation. Similar to isolated germ cells, testicular tissue can be stored frozen prior to grafting while retaining its developmental potential (Honaramooz et al. 2002b, Schlatt et al. 2002b). Moreover, testis tissue xenografting allows experimentation in small rodents while minimizing the number of larger animal donors required and allowing replication of treatments within donor to eliminate a potential donor effect (Rathi et al. 2008). It has been demonstrated that pig testis xenografts have a gene expression profile similar to that of testis tissue in situ (Zeng et al. 2007), and that the cycle of the seminiferous epithelium is conserved in pig and sheep testes xenografts (Zeng et al. 2006), supporting the equivalence of xenograft development and spermatogenesis to those of the normal tissue in situ tissue. Currently, grafting of fresh or preserved testis tissue provides the only technique to obtain male gametes from immature donors, thereby offering an invaluable tool for the conservation of fertility in rare or endangered species (Dobrinski \& Travis 2007), neonatally lethal rodent models (Ohta \& Wakayama 2005, Naughton et al. 2006), and potentially even juvenile cancer patients (Orwig \& Schlatt 2005). Spermatogenesis in testicular tissue formed de novo after grafting of isolated testis cells will further improve the versatility of the xenografting approach. Potential applications (Fig. 3) include co-grafting of germ cells and somatic cells from different donors to define the cellular origin of a given spermatogenic defect, e.g. germ cells from aged donor grafted with somatic cells from young donor, or germ cells from affected donor with somatic cells from wild-type donor and vice versa. Manipulation of specific pathways in germ cells or somatic cells prior to re-aggregation will provide a controlled, accessible system to study processes governing cell-cell interactions during testicular morphogenesis as well as spermatogenesis.

\section{Conclusions and final remarks}

Many aspects of testis development and spermatogenesis remain to be elucidated due mainly to a lack of systems that allow recapitulation and easy manipulation of these complex processes ex situ. In the last years, 
transplantation of testis tissue and isolated cells into immunodeficient mouse hosts has provided novel strategies to explore testis development and spermatogenesis. To date, ectopic grafting of testis tissue has been explored more extensively than ectopic transplantation of isolated testis cells. Factors affecting the survival and development of grafted testis tissue have been identified with the donor species and the age or developmental stage of the donors the most studied so far. Testis cell transplantation is a newer approach that will extend applicability and potential of xenografting to preserve fertility and to study and manipulate spermatogenesis in a variety of mammalian species.

\section{Declaration of interest}

The authors declare that there is no conflict of interest.

\section{Funding}

Work performed in ID's laboratory was supported by National Research Initiative Competitive grant no. 2007-35203-18213 from the USDA Cooperative State Research, Education, and Extension Service, and by grant no. 2 R01 RR17359-06 from the NIH/NCRR.

\section{References}

Arregui L, Rathi R, Megee SO, Honaramooz A, Gomendio M, Roldan ER \& Dobrinski I 2008a Xenografting of sheep testis tissue and isolated cells as a model for preservation of genetic material from endangered ungulates. Reproduction 136 85-93.

Arregui L, Rathi R, Zeng W, Honaramooz A, Gomendio M, Roldan ERS \& Dobrinski I $2008 \mathrm{~b}$ Xenografting of adult mammalian testis tissue. Animal Reproduction Science 106 65-76.

Brinster RL 2007 Male germline stem cells: from mice to men. Science 316 404-405.

Brinster R \& Avarbock MR 1994 Germline transmission of donor haplotype following spermatogonial transplantation. PNAS 91 11303-11307.

Brinster R \& Zimmermann JW 1994 Spermatogenesis following male germ-cell transplantation. PNAS 91 11298-11302.

Dobrinski I 2005 Germ cell transplantation and testis tissue xenografting in domestic animals. Animal Reproduction Science 89 137-145.

Dobrinski I \& Travis AJ 2007 Germ cell transplantation for the propagation of companion animals, non-domestic and endangered species. Reproduction, Fertility, and Development 19 732-739.

Dobrinski I, Avarbock MR \& Brinster RL 1999 Transplantation of germ cells from rabbit and dogs into mouse testes. Biology of Reproduction 61 1331-1339.

Dobrinski I, Avarbock MR \& Brinster RL 2000 Germ cell transplantation from large domestic animals into mouse testes. Molecular Reproduction and Development 57 270-279.

Dufour JM, Rajotte RV \& Korbutt GS 2002 Development of an in vivo model to study testicular morphogenesis. Journal of Andrology 23 635-644.

Gassei K, Schlatt S \& Ehmcke J 2006 De novo morphogenesis of seminiferous tubules from dissociated immature rat testicular cells in xenografts. Journal of Andrology 27 611-618.

Gassei K, Ehmcke J \& Schlatt S 2008 Initiation of testicular tubulogenesis is controlled by neurotrophic tyrosine receptor kinases in a threedimensional Sertoli cell aggregation assay. Reproduction 136 459-469.

Geens M, De Block G, Goossens E, Frederickx V, Van Steirteghem A \& Tournaye H 2006 Spermatogonial survival after grafting human testicular tissue to immunodeficient mice. Human Reproduction 21 390-396.
Gosden RG \& Aubard Y 1996a Why transplant gonadal tissue? In Transplantation of Ovarian and Testicular Tissues, pp 1-15. Eds RG Gosden \& Y Aubard. Texas: Landes Company and Chapman \& Hall.

Gosden RG \& Aubard Y 1996b Transplantation of testicular tissue. In Transplantation of Ovarian and Testicular Tissues, pp 89-97. Eds RG Gosden \& Y Aubard. Texas: Landes Company and Chapman \& Hall.

Herrid M, Vignarajan S, Davey R, Dobrinski I \& Hill JR 2006 Successful transplantation of bovine testicular cells to heterologous recipients. Reproduction 132 617-624.

Hochereau-de-Reviers MT \& Perreau C 1997 Induced differentiation of ovine foetal gonocytes after grafting in the scrotum of nude mice. Reproduction, Nutrition, Development 37 469-476.

Honaramooz A, Megee SO \& Dobrinski I 2002a Germ cell transplantation in pigs. Biology of Reproduction 66 21-28.

Honaramooz A, Snedaker A, Bioani M, Schöler H, Dobrinski I \& Schlatt S $2002 b$ Sperm from neonatal testes grafted in mice. Nature 418 778-781.

Honaramooz A, Behboodi E, Blash S, Megee SO \& Dobrinski I 2003 a Germ cell transplantation in goats. Molecular Reproduction and Development 64 422-428.

Honaramooz A, Behboodi E, Megee SO, Overton SA, Galantino-Homer H, Echelard Y \& Dobrinski I 2003b Fertility and germline transmission of donor haplotype following germ cell transplantation in immunocompetent goats. Biology of Reproduction 69 1260-1264.

Honaramooz A, Li M, Penedo CT, Meyers S \& Dobrinski I 2004 Accelerated maturation of primate testis by xenografting into mice. Biology of Reproduction 70 1500-1503.

Honaramooz A, Megee SO, Rathi R \& Dobrinski I 2007 Building a testis: formation of functional testis tissue after transplantation of isolated porcine (Sus scrofa) testis cells. Biology of Reproduction 76 43-47.

Honaramooz A, Cui X, Kim N \& Dobrinski I 2008a Porcine embryos produced after intracytoplasmic sperm injection using xenogeneic pig sperm from neonatal testis tissue grafted in mice. Reproduction, Fertility, and Development 20 802-807.

Honaramooz A, Megee S, Zeng W, Destrempes MM, Overton SA, Luo J, Galantino-Homer H, Modelski M, Chen F, Blash S et al. 2008b Adenoassociated virus (AAV)-mediated transduction of male germ line stem cells results in transgene transmission after germ cell transplantation. FASEB Journal 22 374-382.

Huang S, Sartini BL \& Parks JE 2008 Spermatogenesis in testis xenografts grafted from pre-pubertal Holstein bulls is re-established by stem cell or early spermatogonia. Animal Reproduction Science 15 1-12.

Izadyar F, Den Ouden K, Stout TA, Stout J, Coret J, Lankveld DP, Spoormakers TJ, Colenbrander B, Oldenbroek JK, Van der Ploeg KD et al. 2003 Autologous and homologous transplantation of bovine spermatogonial stem cells. Reproduction 126 765-774.

Kim Y, Selvaraj V, Pukazhenthi B \& Travis AJ 2007 Effect of donor age on success of spermatogenesis in feline testis xenografts. Reproduction, Fertility, and Development 19 869-876.

Kim Y, Turner D, Nelson J, Dobrinski I, McEntee M \& Travis AJ 2008 Production of donor-derived sperm after spermatogonial stem cell transplantation in the dog. Reproduction 136 823-831.

Kin T, Rajotte RV, Dufour JM \& Korbutt GS 2002 Development of an immunoprivileged site to prolong islet allograft survival. Cell Transplantation 11 547-552.

Kita K, Watanabe T, Ohsaka K, Hayashi H, Kubota Y, Nagashima Y, Aoki I, Taniguchi H, Noce T, Inoue K et al. 2007 Production of functional spermatids from mouse germline stem cells in ectopically reconstituted seminiferous tubules. Biology of Reproduction 76 211-217.

Meachem SJ, Ruwanpura SM, Ziolkowski J, Ague JM, Skinner MK \& Loveland KL 2005 Developmentally distinct in vivo effects of FSH on proliferation and apoptosis during testis maturation. Journal of Endocrinology 186 429-446.

Merchant-Larios H \& Moreno-Mendoza N 2001 Onset of sex differentiation: dialog between genes and cells. Archives of Medical Research $\mathbf{3 2}$ 553-558.

Nagano N, McCarrey JR \& Brinster RL 2001 Primate spermatogonial stem cells colonize mouse testis. Biology of Reproduction 64 1409-1416.

Nagano N, Patrizio P \& Brinster RL 2002 Long-term survival of human spermatogonial stem cells in mouse testes. Fertility and Sterility $\mathbf{7 8}$ 1225-1233. 
Naughton CK, Jain S, Strickland AM, Gupta A \& Milbrandt J 2006 Glial cell-line derived neurotrophic factor-mediated RET signaling regulates spermatogonial stem cell fate. Biology of Reproduction 74 314-321.

Oatley JM, de Avila DM, Reeves JJ \& McLean DJ 2004 Spermatogenesis and germ cell transgene expression in xenografted bovine testicular tissue. Biology of Reproduction 71 494-501.

Oatley JM, Reeves JJ \& McLean DJ 2005 Establishment of spermatogenesis in neonatal bovine testicular tissue following ectopic xenografting varies with donor age. Biology of Reproduction 72 358-364.

Ohta H \& Wakayama T 2005 Generation of normal progeny by intracytoplasmic sperm injection following grafting of testicular tissue from cloned mice that dies postnatally. Biology of Reproduction $\mathbf{7 3}$ 390-395.

Orth JM 1993 Cell biology of testicular development in the fetus and neonate. In Cell and Molecular Biology of the Testis, pp 3-42. Eds C Desjardins \& LL Ewing. New York: Oxford University Press.

Orwig KE \& Schlatt S 2005 Cryopreservation and transplantation of spermatogonia and testis tissue for preservation of male fertility. Journal of the National Cancer Institute. Monographs 3456.

Paris MCJ \& Schlatt S 2007 Ovarian and testicular tissue xenografting: ist potential for germline preservation of companion animals, non-domestic and endangered species. Reproduction, Fertility, and Development 19 771-782.

Paris MCJ, Snow M, Cox S \& Shaw JM 2004 Xenotransplantation: a tool for reproductive biology and animal conservation? Theriogenology $\mathbf{6 1}$ 277-291.

Rathi R, Honaramooz A, Zeng W, Schlatt S \& Dobrinski I 2005 Germ cell fate and seminiferous tubule development in bovine testis xenografts. Reproduction 130 923-929.

Rathi R, Honaramooz A, Zeng W, Turner R \& Dobrinski I 2006 Germ cell development in equine testis tissue xenografted into mice. Reproduction 131 1091-1098.

Rathi R, Zeng W, Megee S, Conley A, Meyers S \& Dobrinski I 2008 Maturation of testicular tissue from infant monkeys after xenografting into mice. Endocrinology 149 5288-5296.

Rodriguez-Sosa JR, Dobson H \& Hahnel A 2006 Isolation and transplantation of spermatogonia in sheep. Theriogenology 66 2091-2103.

Rodriguez-Sosa J, Silvertown J, Foster R, Medin J \& Hahnel A 2009 Transduction and transplantation of spermatogonia into the testis of ram lambs through the extra-testicular rete. Reproduction in Domestic Animals [in press]. DOI: 10.1111/j.1439-0531.2007.01030.x.

Schlatt S, Rosiepen G, Weinbauer GF, Rolf C, Brook PF \& Nieschlag E 1999 Germ cell transfer into rat, bovine, monkey and human testes. Human Reproduction 14 144-150.

Schlatt S, Foppiani L, Rolf C, Weinbauer GF \& Nieschlag E 2002a Germ cell transplantation into X-irradiated monkey testes. Human Reproduction 17 $55-62$.
Schlatt S, Kim SS \& Gosden R 2002b Spermatogenesis and steroidogenesis in mouse, hamster and monkey testicular tissue after cryopreservation and heterotopic grafting to castrated host. Reproduction 124 339-346.

Schlatt S, Honaramooz A, Bioani M, Schöler RH \& Dobrinski I 2003 Progeny from sperm obtained after ectopic grafting of neonatal mouse testes. Biology of Reproduction 68 2331-2335.

Schlatt S, Honaramooz A, Ehmcke J, Goebell PJ, Rubben H, Dhir R, Dobrinski I \& Patrizio P 2006 Limited survival of adult human testicular tissue as ectopic xenograft. Human Reproduction 21 384-389.

Schmidt JA, de Avila JM \& McLean DJ 2006a Grafting period and donor age affect the potential for spermatogenesis in bovine ectopic testis xenografts. Biology of Reproduction 75 160-166.

Schmidt JA, de Avila JM \& McLean DJ 2006 b Effect of vascular endothelial growth factor and testis tissue culture on spermatogenesis in bovine ectopic testis tissue xenografts. Biology of Reproduction 75 167-175.

Shinohara T, Inoue K, Ogonuki N, Kanatsu-Shinohara M, Miki H, Nakata K, Kurome M, Nagashima H, Toyokuni S, Kogishi K et al. 2002 Birth of offspring following transplantation of cryopreserved immature testicular pieces and in vitro microinsemination. Human Reproduction 17 3039-3045.

Skakkebaek NE, Jensen G, Povlsen CO \& Rygaard J 1974 Heterotransplantation of human foetal testicular and ovarian tissue to the mouse mutant Nude. Acta Obstetricia et Gynecologica Scandinavica 53 73-75.

Snedaker AK, Honaramooz A \& Dobrinski I 2004 A game of cat and mouse: xenografting of testis tissue from domestic kittens results in complete cat spermatogenesis in a mouse host. Journal of Andrology 25 926-930.

Turner CD 1938 Intra-ocular homotransplantations of prepubertal testes in the rat. American Journal of Anatomy 63 101-159.

Wistuba J, Mundry M, Luetjens CM \& Schlatt S 2004 Cografting of hamster (Phodopus sungorus) and marmoset (Callithrix jacchus) testicular tissues into nude mice does not overcome blockade of early spermatogenic differentiation in primate grafts. Biology of Reproduction 7 2087-2091.

Zeng W, Avelar GF, Rathi R, Franca LR \& Dobrinski I 2006 The length of the spermatogenic cycle is conserved in porcine and ovine testis xenografts. Journal of Andrology 27 527-533.

Zeng W, Rathi R, Pan H \& Dobrinski I 2007 Comparison of global gene expression between porcine testis tissue xenografts and porcine testis in situ. Molecular Reproduction and Development 74 674-679.

Zhang Z, Hill J, Holland M, Kurihara Y \& Loveland KL 2008 Bovine sertoli cells colonize and form tubules in murine hosts following transplantation and grafting procedures. Journal of Andrology 29 418-430.

Received 16 January 2009

First decision 2 March 2009

Accepted 16 April 2009 